\title{
Don't forget potassium!
}

\author{
Kazunari Kaneko
}

Received: 2 February 2010 / Accepted: 10 February 2010 /Published online: 4 March 2010

(C) Springer-Verlag 2010

\section{Dear Editor,}

I read with great interest the article entitled "The impact of the National Patient Safety Agency intravenous fluid alert on iatrogenic hyponatraemia in children" by Drysdale et al. published in this journal [2]; we would like to draw attention regarding the serum potassium level.

In March 2007, the National Patient Safety Agency (NPSA) issued an alert regarding intravenous fluid (IVF) prescription to hospitalized infants and children (NPSA alert 22). Drysdale et al. supported the alert by demonstrating that the solution recommended by NPSA $(0.45 \%$ or $0.9 \%$ saline/ $5 \%$ dextrose) as maintenance IVF reduced the risk of iatrogenic hyponatremia.

Though I agree in general that hypotonic solution such as $0.18 \%$ saline $/ 4 \%$ dextrose should be replaced by isotonic solution, I am worried about development of iatrogenic hypokalemia which the authors did not mention in the article.

According to the historical article by Holliday and Segar regarding the maintenance need for calories, water, and electrolytes in parenteral fluid therapy for children, daily intake of potassium is recommended to be $2.0 \mathrm{mEq} / 100 \mathrm{cal}$ [3]. Therefore, some pediatricians including me prefer to add potassium into the maintenance fluid whatever that is hypotonic or isotonic [4], though others do not [1, 2]. Armon et al. reported that $23 \%$ of children receiving IVF were hyopokalemic, of whom, $24 \%$ were not receiving potassium in their IVF [1].

Therefore, I recommend that potassium should be added into the isotonic solution for maintenance fluid replacement therapy in children.

\section{References}

1. Armon K, Riordan A, Playfor S, Millman G, Khader A, Paediatric Research Society (2008) Hyponatraemia and hypokalaemia during intravenous fluid administration. Arch Dis Child 93:285-287

2. Drysdale SB, Coulson T, Cronin N, Manjaly ZR, Piyasena C, North A, Ford-Adams ME, Broughton S (2009) The impact of the National Patient Safety Agency intravenous fluid alert on iatrogenic hyponatraemia in children. Eur J Pediatr (Published online: 11 Dec 2009)

3. Holliday MA, Segar WE (1957) The maintenance need for water in parenteral fluid therapy. Pediatrics 19:823-832

4. Kaneko K, Shimojima T, Kaneko K (2004) Risk of exacerbation of hyponatremia with standard maintenance fluid regimens. Pediatr Nephrol 19:1185-1186

K. Kaneko $(\bowtie)$

Department of Pediatrics, Kansai Medical University,

2-3-1 Shin-machi, Hirakata-shi,

Osaka 573 1191, Japan

e-mail:kanekok@hirakata.kmu.ac.jp 